Donald Cardwell has a genius for dismembering persistent myths in the history of science. For example, he deals incisively with the recurring tale that Watt was supposedly indebted to Black's discovery of latent heat before he paid attention to the waste of steam and the consequent loss of power in the Newcomen engine due to the repeated cooling of the cylinder with injected condensing water. Were that really true, Cardwell observes, then we would have a veritable paradox since the high latent heat which Black had discovered should have appeared to be a positive advantage in reducing the amount of condensation and thus helping to maintain steam supply. I hope that Cardwell will press on to further demythologizing in the history of thermodynamics and lead us beyond the standard fare of just Clausius and Kelvin.

Edward E. Daub

\section{Man and Machines}

IEE Centenary Lectures. 1871-1971Electrical Science and Engineering in the Service of Man. Pp. viii +183 . (The Institution of Electrical Engineers: London, 1971.) $£ 5.00$.

OfFICIALLY this is a record of lectures delivered at the Centenary celebrations of the Institution of Electrical Engineers. Its value is certainly much higher. Research scientists probing deeper and deeper into their special subject on a narrower and narrower front become less aware of the activities of their fellow scientists and are less able to read the learned papers of their colleagues. This volume provides an opportunity to read lectures by experts which are written at the level of the non-specialist.

It is not merely an acknowledgment of a century of progress-a milestone in electrical engineering. It is a book to be read and enjoyed by all who dare to think. It takes the whole universe as its setting. Nor is it enough to say that scientists may read for pleasure of the activities of their colleagues. At this time it is almost a duty to do so, for I believe that progress now comes fastest when cross-pollination takes place. It is important that an expert in electrical machines should learn first hand from an authority such as Professor Hodgkin of the nature of nerve impulses. The expert in another discipline may be the person required to fit in that most important piece of the jigsaw which the other authority lacks. There is no doubt that all the authors could have said much more on their subject, given the time and space to do so, and this is perhaps one of the few regrets one may feel about the book as a whole.

The title IEE Centenary Lectures is, I fear, not likely to attract many readers outside the profession, and in particular young people, for whom it would surely serve as the counter to all those who predict the fall of mankind through science. The subjects of the eight lectures which form the main text are seen to be chosen in this context; for example, "Energy, progress and man" and "Disparate world: challenge to education" are two of the titles. Sir Brian Flowers's opening address sets the tone in his last sentence: "He (the engineer) will understand that, in AD 2000, we shall need primroses as much as power stations".

The approach of all the authors is positive-no mere blaming of the scientist as the instrument of doom. Nor is the text "heavy" reading. The opening lecturer felt he had a choice between writing something which was learned but dull or entertaining but silly. I am certain that he succeeded in combining the best of both, as did the other authors, and produced material which was both learned and entertaining. With a title like: "A journey through science from 1871 to 2000", this book might have appeared in all school libraries. I feel it a duty to encourage this. The institution itself might, even at this stage, introduce an exciting dust cover, ensure advertisement of it in such publications as School Science Review, and recommend it for sixth form reading wherever possible.

\section{E. R. Laithwaite}

\section{Using Radioisotopes}

Radioisotopes in Medical Diagnosis. By E. H. Belcher and H. Vetter. Pp. $\mathrm{x}+$ 800. (Butterworth: London, August 1971.) $£ 19.00$.

THE original book by Veall and Vetter on Radioisotope Techniques in Clinical Research and Diagnosis appeared in 1958. Those of us for whom the book has long been a standby have been keenly awaiting a new edition.

The long expected volume has now appeared, albeit with one of the leading names changed and in a multi-author format. With the advances in techniques it was inevitable that the new book should be larger than the old.

In the first chapter, Veall discusses radioisotopes and the various radiations emitted. The section of the chapter dealing with labelled compounds provides a good example of the drawback of the multi-author approach. The Wilzbach technique is described on page 17 and again on page 232 in the chapter by Pearson. The authors of these two chapters are unable to decide whether we have isotope "cows" or cows and indeed whether we "milk" or milk them.

The second chapter contains a good account of the production of the scintillation spectrum and of the various radiation detectors. The next chapter describes the electronic circuitry used in counting equipment. It ends with a section on fault tracing which is much too short to be of practical use and is surely out of place in a book of this kind.

The fifth chapter is a contribution by Belcher, one of the editors, on in vitro counting methods. Here again there is some overlap with a previous chapter.

Trott's chapter on in vivo measurement gives a very good account of linear scanning. There is an unfortunate error in the heading of Table 6.3-"principle" for "principal". The chapter contains illustrations of brain scans. There are similar illustrations in Mallard's chapter some 500 pages later. This highlights one of the defects of the book-almost all the chapters are individually excellent but there is too little cohesion between them.

Chapters on radiation dosimetry and safety aspects follow, and the first part of the book ends with a section on compartmental analysis by Matthews. For readers who are unused to grappling with mathematical symbols, a few practical examples, fully worked out, would have helped enormously.

Most of the remaining chapters are devoted to the investigating of various body systems using particular isotopes. Haxhe explains the principle of dilution analysis in the estimation of body water, extracellular fluid and so on. The simultaneous measurement of these is described in detail--but does anyone indulge in these heroics nowadays? The limited value of such determinations is now recognized and it is perhaps significant that almost none of the 130 references is less than eight years old. One strange point is that body weight is consistently and wrongly written as one word.

It is disappointing to find a chapter on calcium studies which makes no reference to the work from King's College Hospital on the "random walk" concept.

Although all these chapters are authoritative, I feel most of them could have been considerably shortened without undue loss.

Towards the end there are interesting chapters on methods of studying steroid metabolism by Cope and on in vitro tracer tests by Ekins. In the final chapter, Tubiana is given the impossible task of trying to describe the therapeutic uses of radioisotopes in seventeen pages. The section is interesting but is not relevant to the rest of the book and it is a pity that it was included.

Clearly this is a book which should be in every medical radioisotope laboratory. It could by severe editing be made considerably shorter. I also have the feeling that the book could have been written five years ago. Indeed, judging by a footnote, some of it was. As to the price, "outrageous" is scarcely adequate.
J. P. NICHOLSON 